Mark Dingemanse*

\title{
Expressiveness and system integration: On the typology of ideophones, with special reference to Siwu
}

DOI 10.1515/stuf-2017-0018

\begin{abstract}
Ideophones are often described as words that are highly expressive and morphosyntactically marginal. A study of ideophones in everyday conversations in Siwu (Kwa, eastern Ghana) reveals a landscape of variation and change that sheds light on some larger questions in the morphosyntactic typology of ideophones. This article documents a trade-off between expressiveness and morphosyntactic integration, with high expressiveness linked to low integration and vice versa. It also describes a pathway for deideophonization and finds that frequency of use influences the degree to which ideophones can come to be more like ordinary words. The findings have implications for processes of (de) ideophonization, ideophone borrowing, and ideophone typology. A key point is that the internal diversity we find in naturally occurring data, far from being mere noise, is patterned variation that can help us to get a handle on the factors shaping ideophone systems within and across languages.
\end{abstract}

Keywords: ideophones, expressiveness, morphosyntax, prosody, frequency

\section{Introduction}

Many of the world's languages feature a class of marked words that depict sensory imagery, here called ideophones (Voeltz and Kilian-Hatz 2001). Ideophones are noted for their marked forms and highly specific sensory meanings (Dingemanse 2012; Akita 2012), but also for their distinctive morphosyntactic behavior.

The relation between ideophones and morphosyntax is usually negatively defined. Typical claims are "the ideophone stands aloof from any sort of structural connection between itself and any part of the sentence” (Kunene 1965: 22), and "ideophones are a lexical class characterized by the absence of morphological structure" (Johnson 1976: 244). Many authors have also suggested that

*Corresponding author: Mark Dingemanse, Max Planck Institute for Psycholinguistics, PO Box 310, 6500 AH, Nijmegen, The Netherlands, E-mail: mark.dingemanse@mpi.nl. 
ideophones display an antipathy towards negation and questioning (Diffloth 1972; Childs 1988; Kilian-Hatz 2006). Yet any cross-linguistic survey of ideophones yields observations that appear to contradict these tendencies. Bodomo (2006) and De Sousa (2011) describe ideophonic compounds in East and Southeast Asian languages, in which ideophones regularly collocate with a non-ideophonic item. Several authors describe the possibility of negating ideophones (Newman 1968; for Hausa; Kita 1997; for Japanese). Dhoorre and Tosco (1998) describe Somali ideophones as fully-fledged nouns with feminine gender which may have a determiner suffixed to them. In Yucatec Maya, ideophones are regularly derived from existing roots (Le Guen 2012).

How are such apparent counterexamples to be explained? Should we abstract away from them and focus on idealized or canonical cases only? Can we find precise ways to articulate cross-linguistic differences? Can we benefit from proposals like Dwyer and Moshi's (2003) distinction between pure and grammaticalized ideophones, or are there other ways to conceptualize the variation? I address these questions using a combination of primary data and typological evidence from a range of language.

The primary data come from a video corpus of maximally informal social interaction in Siwu, a Ghana-Togo Mountain (Kwa) language spoken in eastern Ghana. The corpus consists of several hours of naturally occurring conversations among friends and relatives - the kind of informal social interaction that is typical of everyday language use around the world (Dingemanse and Floyd 2014). It reveals a landscape of variation and change that is almost as diversified as the cross-linguistic picture, and therefore sheds light on the morphosyntactic typology of ideophones within and across languages.

\section{Defining ideophones}

Many natural languages have words depictive of sensory perceptions like Japanese nyoronyoro 'wriggling motion' and tsurutsuru 'smooth surface' (Gomi 1989), Semelai rõprãp 'something large walking through twigs' and carãlãp 'sound of someone/something entering the undergrowth' (Kruspe 2004), and Gbeya elele 'hair waving gently in a breeze' and bakat bakat 'sound of sandal flapping' (Samarin 1970). Known under the name of 'mimetics' in Japanese linguistics and 'expressives' in South-East Asian languages, the most common cross-linguistic term for such words is 'ideophones' (Diffloth 1972; Kilian-Hatz 2001). Although the word classes of particular languages are best described in language-internal terms, languages may converge on similar solutions that merit 
a common label and a definition in comparative terms (Haspelmath 2010). Ideophones are defined here as MARKED WORDS THAT DEPICT SENSORY IMAGERY (Dingemanse 2012). This definition captures the structural, semiotic, and semantic properties shared by the Japanese, Semelai, and Gbeya word classes exemplified above. It is designed to serve as a cross-linguistic reference point for discussions of language-particular solutions to the generic problem of depicting sensory imagery in words.

Ideophones are MARKED in the sense that they stand out from other words in various ways. Exactly how ideophones are structurally marked in a given language is a fact that belongs to the description of that language. Crosslinguistically, some recurrent ways in which ideophones are structurally marked include skewed phonotactic distributions, feature harmony, more possible syllable structures, special word forms, susceptibility to expressive morphology, relative syntactic independence, and in actual use, foregrounded prosody. Ideophones are wORDS in the sense that they are conventionalized items in the linguistic system and as such can have a language-specific signature: they are distinct from inarticulate noises or creative mimicry. Ideophones DEPICT, that is, they employ a mode of representation that invites people to experience them as iconic performances rather than as arbitrary descriptions. Finally, ideophones depict SENSORY IMAGERY, perceptual knowledge that derives from sensory perception of the environment and the body. The semantic range covered by ideophones differs from language to language and may include perceptions of the external world like sound, motion and visual patterns as well as perceptions of pain, balance, and other inner feelings and sensations.

Ideophones in Siwu conform to this general picture, with language-particular adjustments as expected. The most reliable cues to ideophone status in Siwu are word length (on average, ideophones are longer than verbs and nouns); marked phonotactics, including forms of feature harmony like monovocalicity and monotonality; a set of ideophonic word forms that function as templates; and a corresponding set of expressive morphological processes, i.e. additive reduplication and lengthening (Dingemanse 2015). Siwu ideophones are recognized by native speakers as conventionalized words with definable meanings. In actual use, they are marked as depictions by performative features such as gesture, loudness, intonation, and voice quality. The sensory imagery they depict ranges across the senses, from sight, touch, hearing and kinaesthesia (sense of movement) to taste, color, and interoception (sense of inner physiological conditions). Though they display some affinities with verbs (as we will see below), enough distinctive properties conspire together to consider them a lexical class of their own in the language. 


\section{Ideophonic constructions in Siwu}

The canonical syntactic home of ideophones in Siwu is toward the end of the clause. A finer analysis of patterns of occurrence in the corpus reveals a number of constructions in which ideophones can occur. The five most common constructions, together accounting for $95 \%$ of ideophone tokens, will be discussed below. Table 1: shows the relative frequencies of the five constructions. All examples in the following discussion are taken from the corpus unless otherwise noted.

Table 1: Ideophone constructions in the Siwu corpus.

\begin{tabular}{|c|c|c|}
\hline Construction & Tokens & Proportion \\
\hline Adverbial & 101 & $46 \%$ \\
\hline Complement & 56 & $26 \%$ \\
\hline Holophrase & 27 & $12 \%$ \\
\hline Adjectival & 13 & $6 \%$ \\
\hline Predicative & 11 & $5 \%$ \\
\hline Other & 11 & $5 \%$ \\
\hline Total & 219 & $100 \%$ \\
\hline
\end{tabular}

The Adverbial construction is by far the most common construction, accounting for $46 \%$ of the tokens in the corpus. It has the ideophone occurring as a modifier of a predicate phrase, as in (1) and (2) below. Semantically, the ideophone in this construction type provides a depictive rendering of the scene described in the predicate phrase: the head becoming white fututuu in (1), and the neighborhood being silenced kananaa in (2). ${ }^{1}$
(1) $\quad i-t i$
si $i$-fudza-J
个fututu tutututu个
C.I-head if S.I-be.white-2SG.O IDPH.pure.white EM4
'That your head may become white $\uparrow$ fututututututu $\uparrow$ [pure white]'.

\footnotetext{
1 Arrows (“个”) mark the start and end of prosodic foregrounding, i.e. a markedly high pitch relative to other material in the utterance (Nuckolls 1996; Selting 1994). The gloss EM marks expressive morphology. Glosses follow the Leipzig Glossing Rules. Possibly non-standard abbreviations include: A agreement; C noun class marker; DEP dependent cross-reference marker; DDST and DPRX distal and proximal demonstrative; FP utterance final particle; ING ingressive; PSN person name; $\mathrm{S}$ subject markerl SCR independent subject cross-reference marker. Several of these are combined with the noun class mnemonics I, A, MA, J, SI, KA, KU, MI (e. g. C. $\mathrm{J}$ is the noun class marker for the $\mathrm{J}$ class, A.KU is an agreement marker for the KU class, REL.SI is a relative marker for the si class).
} 
(2) Bo ka-gbàmĭkù ga-ǹgbe ne, ka-̃̃-lo 个ma our C.KA-area A.KA-DPRX FOC ING-he.TP-silence them kanana nanananana $\uparrow$

IDPH.silence $\sim$ EM5

'Our neighbors, he silenced $\uparrow$ them kananananananana $\uparrow$ [silence]'

Many ideophones in this construction tend to collocate with semantically specific verbs; for instance, fututuu with fudza 'be white' and kananaa with lo 'be silent'. Literal translations of these verb-ideophone collocations often have a ring of redundancy to them: "being white pure white", "being silenced silent". This redundancy is due to the fact that a literal translation is an attempt to render in wholly descriptive terms what is in fact a combination of description (predicate phrase) and depiction (ideophone). To overcome this false sense of redundancy, I include the ideophonic material in the English translation. The construction would be syntactically complete without the ideophone, which is here an adverbial modifier of the main predicate and as such can be left out.

Second most common is the Complement construction, accounting for $26 \%$ of corpus tokens. As with the Adverbial construction, here too the ideophone is realized in utterance-final position; but in this case the ideophone is the complement of a two-place predicate. The Complement construction is a type of identity construction, involving relatively general two-place verbs like se 'be', $b a$ 'have', bara 'do' or nys 'look'. In this construction, the ideophone provides a depictive rendering of some property of the subject of the predicate: the subject "looks

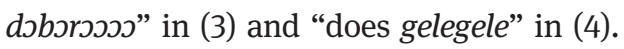

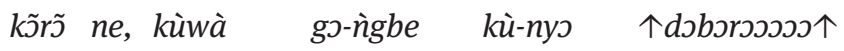

now TP C.KU-stuff A.KU-DPRX S.KU-look IDPH.soft.EM

'Now this stuff here, it looks dכbวrวगวว [soft]'

(4) kà ì-bara gelegele gelegele

ING S.I-do IDPH.shiny EM2

'It'll be gelegelegelegele [shiny]'

Third most common (12\% of corpus tokens) is the Holophrase construction. In it, the ideophone comprises an intonation unit on its own. In example (5), the ideophone tsintsintsin 'neatly' follows as an independent unit after an utterance that is syntactically and intonationally complete, as seen by the final particle and the intonational break. Likewise, in (6), the ideophone totoro 'thick' isn't part of the utterance that precedes it but forms its own intonation unit. 
This construction highlights the ability of ideophones to function as syntactically independent depictive renderings of sensory imagery - as "microscopic sentences”, to use a term by Diffloth (1972: 444).

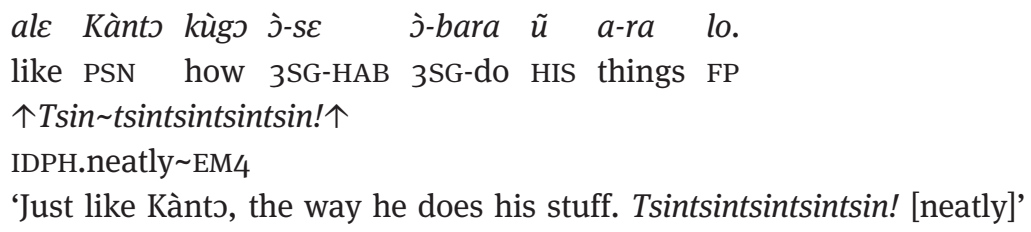

There is a close relationship between the Holophrase and Adverbial constructions. In the latter, the ideophone, though part of the same intonational unit, is syntactically optional and the utterance would be well-formed without it. It is easy to see how this construction can shade into one in which the ideophone follows after the syntactic and prosodic completion of the utterance. For instance in (5), the ideophone tsintsintsin forms an utterance of its own, but it could be construed as adverbially modifying the predicate bara ũ ara 'do his things'. Such cases may function as bridging contexts (Evans and Wilkins 2000: 550) between the Adverbial and Holophrase constructions.

The three constructions discussed so far are the most common ones; together, they account for $84 \%$ of corpus tokens. They all provide a relatively large amount of expressive and syntactic freedom to the ideophone, which occurs at the right clause edge in the Adverbial and Complement constructions and on its own in the Holophrase construction. This is different in the two remaining constructions.

In the Adjectival construction, exemplified in (7) and (8), the ideophone is part of a noun phrase, where it modifies a noun, its adjectival function signaled by the suffix - $a$ (also used to derive adjectives from stative verbs). Ideophones in this construction function much like ordinary derived adjectives. This is shown in (8), which features a conjunction of the adjectivized noun sts ots- $\grave{a}$ 'hot' (from $\grave{j} t \hat{\jmath}$ 'fire') and the adjectivized ideophone yululu-à 'cold' (from yululu 'cold sensation'). 
(7) bo-nà j̀-rẽrẽ gbogboro-à kere 1PL-get C.J-man IDPH.tough-ADJ just

'We've got a sturdy man here'

(8) $n-d u \quad$ stว วtว-à gu mi-yululu-à

C.MI-water fire REDUP-ADJ with A.MI-IDPH.cold-ADJ

'Hot water and cold [water]'

In the Adjectival construction, ideophones are also susceptible to regular processes of tonal change, such as the Raising process following a subset of nouns (Ford 1988). The Adjectival ideophone tokens in the corpus do not happen to be modifying nouns that have a raising effect, so example (9) was elicited as a variation on (7). It shows that the tone of the ideophone gbogboro 'tough' is raised to extra-high following the Raising noun j-turi 'person':

\section{(9) bo-nà j̀-turi gbógbóró-à kere 1PL-get c.J-person IDPH.tough-ADJ just \\ 'We've got a sturdy person here, ${ }^{\text {[elicited] }}$}

The fifth construction is the Predicative construction, in which the ideophone is head of a predicate phrase, occupying the slot in which verbs normally appear. In this construction the ideophone bears subject agreement morphology like a normal verb would. Thus in (10), the ideophone dsborss 'soft' is the head of a predicate, bearing a subject cross reference marker and the ingressive aspectual marker kà. Example (11) has the ideophone gbegbe 'stiff' bearing a dependent subject cross-reference marker and used as a predicate in a relative clause.

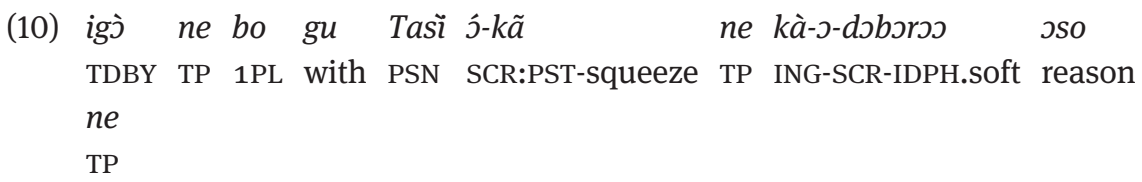

'The day before yesterday, me and Tasì wrung [the palm fruit pulp] ${ }^{2}$ because it was getting soft'

2 This refers to the production of palm oil, in which palm fruit pulp (sïbara) is squeezed in a manual palm oil strainer (kàsukutu) to press out the oil. 


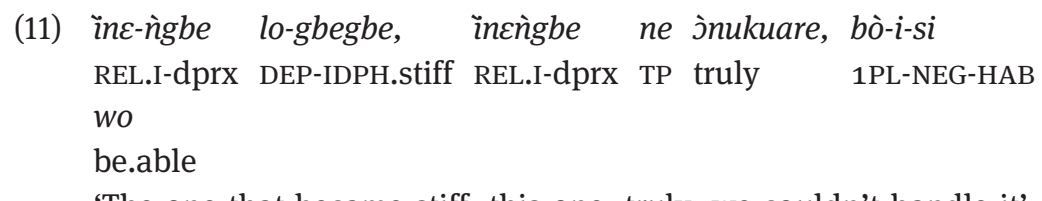

'The one that became stiff, this one, truly, we couldn't handle it'

There is a structural similarity between the Adjectival and Predicative constructions. In both, the ideophone performs a role normally taken up by verbs in the language: functioning as a derived adjective in the first case and as the head of a predicate phrase in the second.

Finally, Table 1 has a category "Other" which lumps together a small number of cases of ideophones occurring in syntactic environments that do not slot neatly into the five types described above. It is possible that some of these would be more common in a corpus that is larger or constituted differently.

\section{Free vs. Bound constructions}

The five constructions in which ideophones occur in Siwu can be divided into two broad groups on the basis of frequency and morphosyntactic behavior. The first group comprises the Adverbial, Complement and Holophrase constructions. In these constructions, the ideophone has a great deal of morphosyntactic freedom, appearing at clause edge or on its own and unburdened by any ordinary morphology. These constructions, which I will term "Free”, account for the great majority of ideophone tokens in the corpus: $84 \%$ (see Table 1). The second group consists of the Adjectival and Predicative constructions, and accounts for $11 \%$ of the ideophone tokens in the corpus. In these constructions, the ideophone is more deeply integrated and more burdened by morphology: I call them "Bound".

Much has been made of the syntactic freedom of ideophones, and rightly so: the data discussed shows that a considerable measure of syntactic independence is the predominant case for Siwu ideophones. However, the less common case of syntactic integration should not be ignored, because it throws light on how ideophones may come to be more like ordinary, non-expressive words. As noted above, ideophones in Bound constructions bear derivational and inflectional morphology, and undergo regular processes of tonal change. Ideophones in Bound constructions thus show greater susceptibility to ordinary morphosyntactic operations. 
Normally (that is, in Free constructions), Siwu ideophones are not negated, nor are they used in question formation - constraints familiar from descriptions of ideophones in other languages. But in Bound constructions, we find that both constraints may be broken. Consider the following data extract, which features two tokens of the ideophone kpokporo in Bound (Predicative) constructions. The first token is embedded in a rhetorical question ("consider our tongue, how kpokporo [hard] is it?"), and the answer by the same speaker features the same ideophone, now negated ("not kpokporo at all").

(12) bo ग-nyagemi go I kànya ngbe ne, ǹda ग-kpokporo

1PL C.J-tongue REL.J LOC mouth here TP, how S.J-IDPH.hard ग-Sغे?

S.J-HAB

'The tongue in our mouth, how kpokporo [hard] is it?'

i-i-kpokporo.

it-NEG-IDPH.hard

'It isn't kpokporo [hard]'

Free and Bound constructions may furthermore be different in terms of information structure. Ideophones are often associated with the foregrounding and presentation of new information, something that fits well with their prosodic distinctiveness (Nuckolls 1996; Alpher 2001; Kita 1997: 395-398; Güldemann 2008: 286-288). For Siwu ideophones in Free constructions, this appears to be the case as well. In Bound constructions on the other hand, ideophones are often used to convey backgrounded and old/given information. For instance, in (10) above, the speaker's main point was not to highlight the palm fruit pulp becoming dsborss 'soft', but rather the fact that she did the work the day before yesterday. Likewise the primary business of the ideophone in (11) is not to provide a depiction of sensory imagery, but to establish reference to a prior topic of speech.

Ideophones in the Free and Bound constructions differ not only in frequency and degree of morphosyntactic integration, but also in terms of prosody and expressive morphology. Expressive morphology (Zwicky and Pullum 1987) refers to the additive, playful, orderly processes of expressive reduplication and lengthening that we often find applied to ideophonic words in actual instances of use. For instance, in the Siwu corpus, we find the ideophone gelegele 'shiny' sometimes in its basic form gelegele, but we also find it as gelegele gelegele (see (4) above), in which case the extra reduplications are counted as expressive morphology. In Free constructions, ideophones show ample expressive morphology (marked by EM in the examples) as well as prosodic foregrounding 
(marked by arrows “个” in the examples), and they are impervious to processes of tonal change. In Bound constructions on the other hand, the ideophones behave just like ordinary words: instead of flaunting expressive morphology, they come to bear ordinary morphology, and instead of carving out their own intonational contour they yield to the intonational contour of the sentence, including any processes of tonal change that may apply.

Table 2 visualizes this inverse relation by showing the five constructions along with two indicators of syntactic integration and two indicators of expressiveness. "Ordinary morphology" concerns whether the ideophone bears any ordinary derivational or inflectional morphology normally reserved for other word classes; "tonal change" is the susceptibility of the ideophone to processes of tonal sandhi, a useful indicator for Siwu because tonal change is regimented partly on the basis of morphosyntactic domains (Ford 1988). "Expressive morphology" concerns the susceptibility of the ideophonic word to additive playful word formation processes like reduplication and lengthening, while "prosodic foregrounding" is the marked stress and intonational foregrounding that often mark ideophones as performances (Nuckolls 1996).

Table 2: Syntactic integration and expressive features of Siwu ideophones.

\begin{tabular}{|c|c|c|c|c|c|c|}
\hline & & \multicolumn{3}{|c|}{ Free constructions } & \multicolumn{2}{|c|}{ Bound constructions } \\
\hline & & Holophrase & Adverbial & Complement & Adjectival & Predicative \\
\hline \multirow[t]{2}{*}{ syntactic integration } & ordinary morphology & $x$ & $x$ & $x$ & $\checkmark$ & $\checkmark$ \\
\hline & tonal change & $x$ & $x$ & $x$ & $\checkmark$ & $\checkmark$ \\
\hline \multirow[t]{2}{*}{ expressive features } & $\begin{array}{l}\text { expressive } \\
\text { morphology }\end{array}$ & $\checkmark$ & $\checkmark$ & $\checkmark$ & $x$ & $x$ \\
\hline & $\begin{array}{l}\text { prosodic } \\
\text { foregrounding }\end{array}$ & $\checkmark$ & $\checkmark$ & $\checkmark$ & $x$ & $x$ \\
\hline
\end{tabular}

While I have found that these particular measures of integration and expressiveness are useful for Siwu, there would be several more conceivable measures of both. Other possible indicators of morphosyntactic integration include: whether the ideophone is syntactically optional or not; whether the ideophone occurs at the edge of the utterance or more embedded; whether it does or does not regularly collocates with a non-ideophonic item; whether the ideophone is part of the same or a different intonational unit; and whether there is (or can be) a pause between utterance and ideophone. Other possible indicators of expressivity include: loudness, locus of intonational peak, and co-occurrence of iconic gestures (as a proxy for the expressiveness of the performance). 
As we see, there is a trade-off between syntactic integration and expressiveness. Ideophones in Free constructions are devoid of syntactic integration and feature expressive morphology and prosodic foregrounding; conversely, ideophones in Bound constructions are subject to morphosyntactic integration and show a lack of these same expressive features. In other words, syntactic freedom means expressive freedom and tighter integration of the ideophone into the sentence comes with a loss of expressivity.

One way to understand this trade-off is by reference to the nature of ideophones. In their prototypical form, ideophones are best understood as fundamentally depictive words: words in which verbal material is performatively foregrounded in order to depict (enact, perform, demonstrate) sensory imagery. As spoken words, ideophones are part of the linear, temporally unfolding speech stream. To be recognizable as depictive performances, they somehow have to be marked as distinct and independent from the descriptive material surrounding them (Kunene 1965). This is achieved by the combination of expressive features and syntactic independence we typically see with ideophones. Conversely, in Bound constructions, ideophones tend to lack expressive features and are more fully integrated into the utterance; in other words, they are designed to be recognizable as depictive performances. Another way to capture the distinction between Free and Bound constructions is therefore to note that ideophones appear to be produced as depictions in the first, but as descriptions in the second.

So far I have provided a synchronic, system-related explanation for the interaction observed. But there is also a diachronic, change-related dimension to the story, and to this we now turn.

\section{Ideophones and de-ideophonization}

How is it that some ideophones may come to be recruited in Bound constructions to do the work of conveying backgrounded information and plain descriptions? A first thing to ask is whether there is anything special about the kinds of ideophones that occur in Bound constructions with regard to form, meaning, or use. Are all ideophones equally likely to occur in both Free and Bound constructions?

Table 3 lists the ideophones from the Siwu corpus that occur in Bound constructions. They show diversity typical of the ideophone inventory as a whole, with all major ideophonic word forms and a wide range of meanings represented. However, most ideophones that occur in Bound constructions also 
Table 3: Ideophones that appear in Bound constructions in the corpus.

\begin{tabular}{|c|c|c|c|c|}
\hline Ideophone & & Total tokens & Free & Bound \\
\hline dכbכrככ & 'soft' & 13 & 9 & 4 \\
\hline pokכsכo & 'quiet/slow' & 11 & 10 & 1 \\
\hline gbegbe:gbe & ‘stiff' & 9 & 8 & 1 \\
\hline kpokporo & 'hard' & 8 & 5 & 3 \\
\hline wĩrīwĩri & 'many small things' & 6 & 4 & 2 \\
\hline gbogboro & 'tough' & 5 & 1 & 4 \\
\hline kpïnàkpīnà & ‘black’ & 5 & 2 & 3 \\
\hline yuayua & 'burning' & 4 & 3 & 1 \\
\hline godor & 'crooked' & 3 & 2 & 1 \\
\hline melemele & 'sweet' & 2 & 0 & 2 \\
\hline yululu & 'cold' & 2 & 1 & 1 \\
\hline nyanyarï & 'dirty/bad' & 1 & 0 & 1 \\
\hline Total tokens & & 69 & 45 & 24 \\
\hline
\end{tabular}

occur in Free constructions, and more frequently so. Perhaps the probability of occurring in Bound constructions is not the same for all ideophones. Could it be that ideophones that are especially frequently used are more prone to occur in Bound constructions?

In the corpus, there are 219 ideophone tokens of 104 unique types. As with any linguistic behavior, there is a markedly asymmetrical frequency distribution (Zipf 1935): a small number of ideophones is used relatively often while a larger proportion is used more rarely. The average token frequency of ideophones is 2.4, with 84 ideophones occurring at this frequency or lower, and 20 ideophones occurring with higher frequency.

If there was no relation between frequency and morphosyntactic integration, we would expect the ideophones occurring in Bound constructions to be found in proportionate amounts among low frequency as well as high frequency ideophones. Instead, they appear to be strongly skewed towards the higher frequency range: 9 out of 12 ideophones occurring in Bound constructions are from the subset of high frequency ideophones (Table 4). Though the numbers are relatively modest (a larger corpus would provide stronger evidence), the skewness is confirmed by a statistical test (Fisher's Exact $p<0.0001$, odds ratio 21), high frequency ideophones are 21 times more likely than low frequency ideophones to occur in Bound constructions.

This implies a pathway for deideophonization. Ideophones, normally free, can be bound and pressed into service as ordinary words. The more frequently an ideophone is used, the easier it may be recruited as an ordinary word, and 
Table 4: Ideophones by corpus frequency and occurrence in Free and Bound constructions.

\begin{tabular}{lrrr}
\hline & Low frequency & High frequency & \\
\hline Occurs in Free only & 81 & 11 & 92 \\
Occurs in Free and Bound & 3 & 9 & 12 \\
& 84 & 20 & 104 \\
\hline
\end{tabular}

the more likely it is to be found without expressive features. The erosive role of frequency in language change is of course well known (Zipf 1935; Bybee 2007). Possibly, high frequency of use tends to wear off the features - like performative foregrounding and expressive morphology - that mark ideophones as special, and opens up the way for them to be used as ordinary words.

In Siwu, ideophones that occur in Bound constructions acquire verb-like properties. The de-ideophonization scenario sketched here predicts the existence of deideophonic verbs in Siwu which still share some features with ideophones. Such cases are indeed found. A good example is the item dzoroo 'be far'. Like an ideophone, it can be used occasionally in the Adverbial and Complement constructions, but it is most commonly used as a predicate, in which case its long final vowel is shortened, as in Kùbe J-dzoro \{PLN SCR-be. far\} 'Kùbe is a far place'. This form appears to waver between ideophone and verb status, so much so that it is difficult to decide whether to transcribe it with a long final vowel (conforming to a common ideophone template) or a short final one (conforming to verb status).

The perspective adopted here allows us to make a corrective note on a previous proposal concerning ideophones and deideophonization by Dwyer and Moshi (2003). Dwyer and Moshi adopt a basic opposition between "expressive" and "analytic" dimensions of meaning from work by Diffloth (1972) and Kita (1997), and they suggest there is a corresponding distinction between ideophones that are "pure", that is, found in the expressive dimension, and those that are "grammaticalized", i.e. found in the analytic dimension. On their account, this opposition appears to be dichotomous: an ideophone is either pure or grammaticalized.

One challenge for this dichotomization of the ideophone inventory is that it presents an essentially static perspective where a dynamic, usage-based perspective would better fit the data. Thus in Siwu (and no doubt in other languages), one and the same ideophone type may be used in a Free construction in one case and in a Bound one in another. This is readily illustrated by a pair of examples that we have seen before, (3) and (10), repeated below for convenience. 


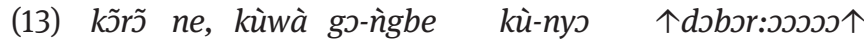
now TP stuff A.KU-DPRX S.KU-look IDPH.soft.EM

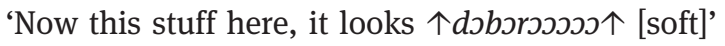

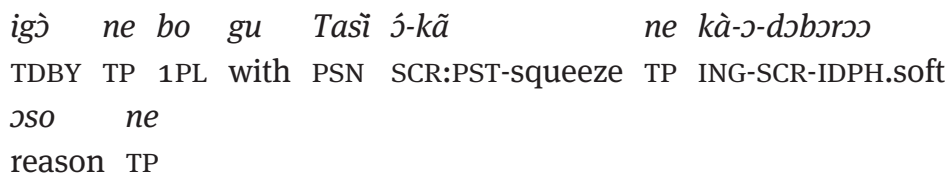

Under Dwyer and Moshi's proposal, it would be impossible to choose whether the Siwu ideophone dsbsros 'soft' is pure or grammaticalized: its performative foregrounding, expressive lengthening and syntactic freedom in (13) would suggest the former category, while its intonational inconspicuousness and syntactic embedding in (14) would suggest the latter. This shows that the degree to which ideophones are pure or grammaticalized is probably better thought of as a feature of tokens (actual instances of use) than of types (lexical entries). A simple division of the ideophone inventory into pure vs. grammaticalized would ignore a seemingly fuzzy area that is in fact highly informative. Here we see an item that behaves as a prototypical ideophone in one case and more like an ordinary verb in the next. Importantly however, in both cases, the behaviour is in line with the inverse relation between expressiveness and system integration, and so what may look like a puzzling case from one perspective is seen to pattern just as expected in the analysis developed here.

One intuition from Dwyer and Moshi worth preserving is the idea that ideophones may vary in the degree to which they show canonically free and expressive behavior. Over time, some ideophones may become more grammatically integrated (or deideophonized), and the frequency-based process observed above provides one way to understand how this may happen. Corpus data allows us to observe such processes of language change at the primary causal level, illustrating how languages are, in the words of Merleau-Ponty, "the silt and sedimentation of acts of parole” (Merleau-Ponty 1945: 229).

\section{Implications for ideophone typology}

Let us take stock of the ground covered so far. We have seen that Siwu ideophones in a conversational corpus break up into five basic constructions. 
Evidence from relative frequency and morphosyntax motivates a broad distinction between Free and Bound constructions. Features like performative foregrounding and expressive morphology are rampant in Free but nearly absent in Bound constructions; conversely, syntactic integration and attendant ordinary morphology are present in Bound but absent in Free constructions.

These findings can be understood in functional terms. In Free constructions (the most common case), ideophones are presented as depictions, their depictive status signaled and supported by syntactic independence and expressiveness. In Bound constructions, there is less room for a depictive presentation, as ideophones are more deeply integrated into the utterance and show fewer expressive features. The findings can also be understood in frequency-based terms: the morphosyntactic flexibility (and ultimately, the degree of integration) of ideophones appears to relate to their frequency. The ideophone constructions of Siwu can be placed on a continuum, with Free constructions showing a low degree of integration and a high degree of expressiveness, and Bound constructions showing the reverse (Figure 1).

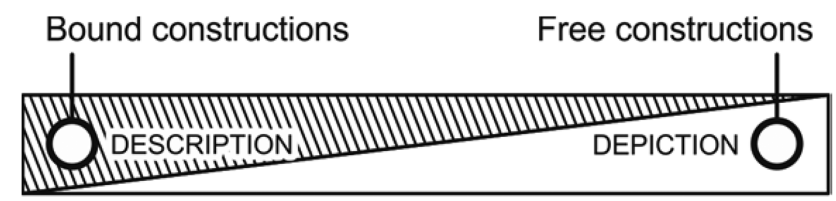

WI morphosyntactic integration $\square$ expressiveness

Figure 1: The Free and Bound ideophone constructions of Siwu on the integration and expressiveness continuum.

Is this indeed a continuum or could it be a categorical distinction? In Siwu, the constructions happen to fall into two groups on the extreme sides of the continuum, yet conceivably, in some languages the array of ideophone constructions will show a more varied distribution. The analog, gradient nature of many expressive features (prosody and expressive morphology) suggests that expressiveness is not an all or nothing affair; indeed we know that expressive features can be overlaid on ordinary speech (Liberman 1975; Shintel et al. 2006). Similarly, morphosyntactic integration is not a simple binary feature: there are many possible degrees of integration in every language. For this reason, it seems reasonable to present the system integration/expressiveness dynamic as a continuum. 
The Siwu facts have broader typological relevance, as the functional and frequency-based proposals offered here are general: (1) morphosyntactic independence goes hand in hand with expressiveness to help signal the depictive nature of ideophones; (2) morphosyntactic integration goes with a lack of expressiveness, providing a pathway for deideophonization; (3) frequency of use is one of the factors that may contribute to increased morphosyntactic flexibility, integration, and ultimately deideophonization. The generality of these proposals predicts that the morphosyntax of ideophones in other languages should pattern in similar ways, at least with respect to grammatical integration and expressiveness. In this sense, the constructional patterns and the variation described here for one language are a microcosm of the diversity we find across languages.

Indeed we find similar patterns of deideophonization going along with morphosyntactic integration, for instance in the Bantu languages of SouthAfrica, where ideophones can be turned into ordinary nouns by the addition of noun class morphology (Mtintsilana and Morris 1988). The reverse case, which may be called "ideophonization", is also attested. In Yucatec Maya, one and the same root word can be instantiated as a verb or as an ideophone (Le Guen 2012). Verbal status is marked by syntactic integration and association with aspectual forms. Ideophonic status on the other hand is marked by patterns of expressive morphology, syntactic isolation (e.g. occurrence at utterance-edge), and other tell-tale signs of depiction such as special prosody and iconic gestures. The cases pattern as expected: deideophonization turns depictive signs into descriptive ones by decreasing expressiveness and increasing morphosyntactic integration; ideophonization turns descriptive signs into depictive ones by increasing expressiveness and decreasing morphosyntactic integration (Figure 2).
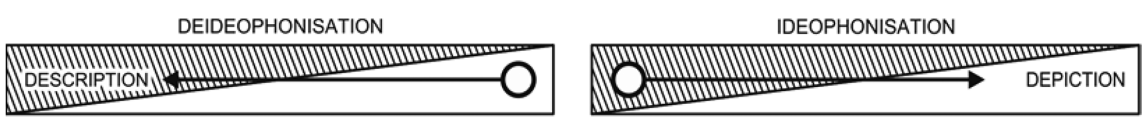

(1] morphosyntactic integration $\square$ expressiveness

Figure 2: Deideophonization and ideophonization.

Further predictions arise with regard to ideophone borrowing. Ideophones have rarely been studied from areal or comparative perspectives, partly due to beliefs that they are unstable and have no clear etymologies (Childs 1994a; Blench 2010). One of the factors influencing the borrowability of linguistic items is the degree of system integration: this explains, for instance, why grammatical 
morphemes are less commonly borrowed than free-standing content words (Matras 2007; Enfield 2008). It follows that if ideophones are typically characterized by a low degree of morphosyntactic integration, this should increase their borrowability. Though the picture is complicated by the fact that the use of ideophones is also influenced by sociolinguistic attitudes (Childs 1994b) and language ideologies (Nuckolls 2004), the basic idea seems to be confirmed by the few studies that have looked at ideophones in (post-)contact situations. For instance, Emeneau (1969) found a substantial number of shared ideophones in the Indian linguistic area, Bartens (2000) documented widespread borrowing of ideophones from West-African substrate languages into Atlantic creoles, and Nakagawa (2011) found evidence of ideophone borrowing between !Xóõ (Taa, Southern Khoisan) and G|ui (Khwe, Central Khoisan) in Botswana. In light of the present study, these findings are precisely what would be expected. The areal distribution and borrowability of ideophones is likely to be a fruitful locus for further research.

A general implication of the findings presented here is that the morphosyntactic typology of ideophones should ultimately be based on descriptions that are sensitive to microvariation within and across languages. Simple statements of the type that ideophones have no syntax are of limited value. We know now that most languages have multiple constructions in which ideophones can be used, and these constructions will in all likelihood differ from each other along the lines sketched here (as well as in other ways). Cataloguing such differences on the basis of evidence from naturally occurring data will contribute to the description of the morphosyntax of ideophone systems in individual languages and will make it possible to refine and replicate the findings here crosslinguistically.

So far I have taken a splitter's perspective: I have argued that describing fine morphosyntactic variation is important and valuable both for individual language description and cross-linguistic typology. A lumper's perspective might also be fruitful for typological purposes, for example by abstracting away from the microvariation in constructions and comparing not individual constructions, but languages. This could be done by taking the most common ideophone construction type (and its expressive profile) as representative for the language, though a more precise, quantifiable way would be to construe a weighted average based on morphosyntactic and expressive features across constructions.

The lumper's perspective allows us to move towards a more scalar conception of the differences between ideophone systems, at least with regard to morphosyntactic integration and expressiveness. If we learn that in Semai, ideophones "are not at all integrated in the syntax of the language and 
function mostly in the manner of independent clauses, all by themselves" (Diffloth 1976: 256), presumably this is a fact about the main ideophone construction(s) in the language, which enables us to place Semai on the far right of a tentative continuum (Figure 3). If ideophones in Somali are "fully-fledged nouns" which "may have a definite or anaphoric determiner suffixed to them" (Dhoorre and Tosco 1998: 129), then Somali lies more on the left of such a continuum. The decreased expressivity predicted by this placement would be supported by one of Dhoorre and Tosco's observations: "Somali ideophones look much less 'pragmatically bound' than their counterparts in other African languages; it is tempting to think that this is in correlation with their noun-like character" (p. 130). Intermediate positions might be occupied by languages like Japanese, which has separate groups of nominal and adverbial ideophones that participate in sentential syntax to different degrees (Kita 1997; Akita 2009), or Siwu, where ideophones are usually expressive but may sometimes be used in more syntactically integrated contexts.

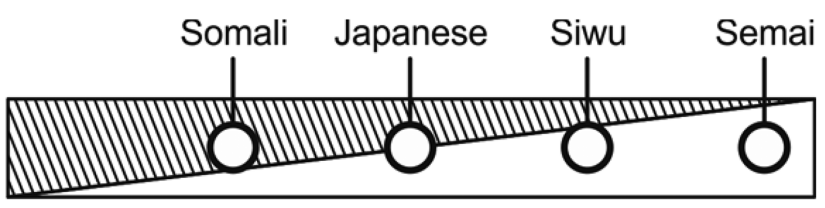

四 morphosyntactic integration $\square$ expressiveness

Figure 3: Schematic representation of some ideophone systems on a tentative integration vs. expressiveness continuum.

\section{Conclusions}

This article has presented a data-driven case for a more fine-grained morphosyntactic typology of ideophones. The argument has been that the linguistic diversity we find, far from being noise to be swept under the rug, is patterned variation that can help us to get a grip on some of the factors shaping ideophone systems.

A small conversational corpus showed similarities and differences between the five main ideophonic constructions in Siwu and revealed a trade-off between morphosyntactic integration and expressivity. Two general, partly orthogonal explanations were proposed: (1) The inverse relation between morphosyntactic integration and expressive features can be explained by reference to the depictive nature of ideophones. (2) Frequency of use can determine which ideophones are more likely to be subject to deideophonization. 
The observations made here are one slice through the multidimensional space of the morphosyntactic typology of ideophones. They help explain why ideophones prototypically enjoy a great deal of syntactic freedom; they suggest how some ideophones may come to be more like ordinary words; and they give us one way to state more explicitly what makes, say, the ideophone system of Somali different from that of Siwu and these two different again from Japanese. Other dimensions of variation await further investigation. For instance, the internal differentiation of ideophone inventories also interacts with questions of morphosyntax. In many languages there appears to be a broad division between onomatopoeic ideophones and the rest, where the former tend to have a more peripheral syntactic realization than the latter (Kilian-Hatz 1999; Akita 2009). Other subclasses of ideophones may have their own morphosyntactic properties, for instance smell words in Nilotic (Storch and Vossen 2007) and body-part insultatives in Central-Nigerian languages (Blench 2010). The morphosyntactic typology of ideophones constitutes a major area for future research. Conversational corpora are likely to play an essential role in this enterprise, as it is only in naturally occurring speech that we see the full range of variation and have access to crucial variables like expressive features and frequency.

Ideophones have often been cast as exotic words, insulated from the rest of the linguistic system. Though that proves to be an oversimplification, there is an important kernel of truth to it. Ideophones are designed to be recognizable as words employing a depictive mode of representation, distinct from surrounding descriptive speech. Nevertheless, ideophones are also conventionalized words that can grow roots in the broader linguistic system. Here we have examined this process using corpus data, with implications for our understanding of the morphosyntax and typology of ideophones. In time, the rise of accounts built on rich primary data will help us to understand ideophone systems within and across languages, in their synchronic and diachronic dimensions.

Acknowledgements: I am grateful to Nick Enfield, Kimi Akita, Steve Levinson, Lila San Roque, Felix Ameka, Eva van Lier, and an anonymous reviewer for helpful comments on earlier versions. Special thanks go to Rev. A.Y. Wurapa, Jdime Kanairo, and the wider Mawu community of Akpafu-Mempeasem, Ghana, for supporting this research. Funding has come from the Max Planck Society for the Advancement of Science, the European Research Council (grant 240853), and the Netherlands Organization for Scientific Research (Veni 016.154.087). This paper incorporates and revises some work reported in an unpublished dissertation by the author. The bulk of the paper dates from 2012. 
After a publishing delay due to circumstances beyond the control of the author, it has been updated in early 2016 to incorporate some references to work that appeared since.

\section{References}

Akita, Kimi. 2009. A grammar of sound-symbolic words in Japanese: Theoretical approaches to iconic and lexical properties of Japanese mimetics. PhD dissertation, Kobe University. http://www.lib.kobe-u.ac.jp/handle_gakui/D1004724.

Akita, Kimi. 2012. Toward a frame-semantic definition of sound-symbolic words: A collocational analysis of Japanese mimetics. Cognitive Linguistics 23(1). 67-90.

Alpher, Barry. 2001. Ideophones in interaction with intonation and the expression of new information in some indigenous languages of Australia. In F. K. Erhard Voeltz \& Christa Kilian-Hatz (eds.), Ideophones, 9-14. Amsterdam: John Benjamins.

Bartens, Angela. 2000. Ideophones and sound symbolism in Atlantic Creoles. Saarijärvi: Gummerus Printing.

Blench, Roger. 2010. The sensory world: Ideophones in Africa and elsewhere. In Anne Storch (ed.), Perception of the invisible: Religion, historical semantics and the role of perceptive verbs, 275-296. Cologne: Köppe.

Bodomo, Adams B. 2006. The structure of ideophones in African and Asian languages: The case of Dagaare and Cantonese. In John M. Mugane, John P. Hutchison \& Dee A. Worman (eds.), Selected Proceedings of the 35th Annual Conference on African Linguistics: African Languages and Linguistics in Broad Perspectives, 203-213. Harvard: Harvard University Press.

Bybee, Joan L. 2007. Frequency of use and the organization of language. Oxford: Oxford University Press.

Childs, G. Tucker. 1988. The phonology and morphology of Kisi. PhD dissertation, University of California, Berkeley.

Childs, G. Tucker. 1994a. African Ideophones. In Leanne Hinton, Johanna Nichols \& John J. Ohala (eds.), Sound symbolism, 178-204. Cambridge: Cambridge University Press.

Childs, G. Tucker. 1994b. Expressiveness in contact situations: The fate of African ideophones. Journal of Pidgin and Creole languages 9(2). 257-282.

De Sousa, Hilário. 2011. Ideophonic compounds in East and Southeast Asia, presented the Association for Linguistic Typology 9th Biennial Conference, Hong Kong.

Dhoorre, Cabdulqaadir Salaad \& Mauro Tosco. 1998. 111 Somali ideophones. Journal of African Cultural Studies 11(2). 125-156.

Diffloth, Gérard. 1972. Notes on expressive meaning. Chicago Linguistic Society 8. 440-447.

Diffloth, Gérard. 1976. Expressives in Semai. Oceanic Linguistics Special Publications (13). 249-264.

Dingemanse, Mark. 2012. Advances in the cross-linguistic study of ideophones. Language and Linguistics Compass 6(10). 654-672.

Dingemanse, Mark. 2015. Ideophones and reduplication: Depiction, description, and the interpretation of repeated talk in discourse. Studies in Language 39(4). 946-970. 
Dingemanse, Mark \& Simeon Floyd. 2014. Conversation across cultures. In Nick J. Enfield, Paul Kockelman \& Jack Sidnell (eds.), Cambridge handbook of linguistic anthropology, 434-464. Cambridge: Cambridge University Press.

Dwyer, David \& Lioba Moshi. 2003. Primary and grammaticalized ideophones. In John M. Mugane (ed.), Linguistic typology and representation of African languages, 173-185. Trenton: Africa World Press.

Emeneau, Murray B. 1969. Onomatopoetics in the Indian linguistic area. Language 45(2). 274-299.

Enfield, Nick J. 2008. Transmission biases in linguistic epidemiology. Journal of Language Contact 2. 299-310.

Evans, Nicholas \& David Wilkins. 2000. In the mind's ear: The semantic extensions of perception verbs in Australian languages. Language 76(3). 546-592.

Ford, Kevin. 1988. Structural features of the Central Togo languages. In Mary Esther \& Kropp Dakubu (ed.), The languages of Ghana, 126-154. London: Kegan Paul.

Gomi, Taro. 1989. An illustrated dictionary of Japanese onomatopoeic expressions. Transl. by J. Turrent. Tokyo: Japan Times.

Güldemann, Tom. 2008. Quotative indexes in African languages: A synchronic and diachronic survey. Berlin: Mouton de Gruyter.

Haspelmath, Martin. 2010. Comparative concepts and descriptive categories in crosslinguistic studies. Language 86(3). 663-687.

Johnson, Marion M. 1976. Toward a definition of the ideophone in Bantu. Working Papers in Linguistics 21. 240-253.

Kilian-Hatz, Christa. 1999. Ideophone: Eine typologische Untersuchung unter besonderer Berücksichtigung afrikanischer Sprachen. Habilitationsschrift, Universität zu Köln.

Kilian-Hatz, Christa. 2001. Universality and diversity: Ideophones from Baka and Kxoe. In F. K. Erhard Voeltz \& Christa Kilian-Hatz (eds.), Ideophones, 155-163. Amsterdam: John Benjamins.

Kilian-Hatz, Christa. 2006. Ideophones. In Keith Brown (ed.), Encyclopedia of language \& linguistics, 508-512. Oxford: Elsevier.

Kita, Sotaro. 1997. Two-dimensional semantic analysis of Japanese mimetics. Linguistics 35. 379-415.

Kossmann, Maarten. in press. Sub-Saharan influence on Tuareg morphology: The case of full reduplication. In [Festschrift], edited by Rainer Vossen.

Kruspe, Nicole. 2004. A grammar of Semelai. Cambridge: Cambridge University Press.

Kunene, Daniel P. 1965. The ideophone in Southern Sotho. Journal of African Languages 4. 19-39.

Le Guen, Olivier. 2012. Ideophones in Yucatec Maya. In Proceedings of the SSILA V Conference, 26. Austin, TX.

Liberman, Mark. 1975. The intonational system of English. PhD dissertation, MIT.

Matras, Yaron. 2007. The borrowability of structural categories. In Yaron Matras \& Jeannette Sakel (eds.), Grammatical borrowing in cross-linguistic perspective, 31-73. Berlin/New York: Mouton de Gruyter.

Merleau-Ponty, Maurice. 1945. Phénoménologie de la perception. Paris: Gallimard.

Mtintsilana, Priscilla N. \& Rose Morris. 1988. Terminography in African languages in South Africa. South African Journal of African Languages 8(4). 109-113. 
Nakagawa, Hirosi. 2011. A first report on G|Ui ideophones. In Osamu Hieda, Christa König \& Hirosi Nakagawa (eds.), Geographical typology and linguistic areas: With special reference to Africa, 279-286. Amsterdam/Philadelphia: John Benjamins.

Newman, Paul. 1968. Ideophones from a syntactic point of view. Journal of West AfricanLanguages 5. 107-117.

Newman, Paul. 2001. Are ideophones really as weird and extra-systematic as linguists make them out to be? In F. K. Erhard Voeltz \& Christa Kilian-Hatz (eds.), Ideophones, 251-258. Amsterdam: John Benjamins.

Nuckolls, Janis B. 1996. Sounds like life: Sound-symbolic grammar, performance, andcognition in Pastaza Quechua. New York: Oxford University Press.

Nuckolls, Janis B. 2004. To be or to be not ideophonically impoverished. In Wai Fong Chiang, Elaine Chun, Laura Mahalingappa \& Siri Mehus (eds.), SALSA XI: Proceedings of the Eleventh Annual Symposium about Language and Society, 131-142. Austin: University of Texas.

Samarin, William J. 1970. Inventory and choice in expressive language. Word 26. 153-169.

Selting, Margret. 1994. Emphatic speech style - with special focus on the prosodic signalling of heightened emotive involvement in conversation. Journal of Pragmatics 22(3/4). 375-408.

Shintel, Hadas, Howard C. Nusbaum \& Arika Okrent. 2006. Analog acoustic expression in speech communication. Journal of Memory and Language 55(2). 167-177.

Storch, Anne \& Rainer Vossen. 2007. Odours and colours in Nilotic: Comparative case studies. In Mechthild Reh \& Doris L. Payne (eds.), Advances in Nilo-Saharan linguistics, proceedings of the 8th Nilo-Saharan Linguistics Colloquium, 101-121. Köln: Rüdiger Köppe.

Voeltz, F. K. Erhard \& Kilian-Hatz, Christa (eds.) 2001. Ideophones. Amsterdam: John Benjamins. Zipf, George K. 1935. The psycho-biology of language. Boston: Houghton Mifflin.

Zwicky, Arnold M. \& Geoffrey K. Pullum. 1987. Plain morphology and expressive morphology. In John Aske, Natasha Beery, Laura Michaelis \& Hana Filip (eds.), Proceedings of the Thirteenth Annual Meeting of the Berkeley Linguistics Society, VII. 330-340. Berkeley: Berkeley Linguistics Society. 